\title{
Comparative study of Methotrexate and Cyclosporine in the treatment of Psoriasis
}

\author{
Karn $D^{1}$, Amatya $A^{2}$, Khatri $R^{3}$
}

${ }^{1}$ Lecturer, Department of Dermatology and Venereology, Dhulikhel Hospital , KUTH, Dhulikhel, Kavre.

${ }^{2}$ Lecturer, Department of Dermatology and Venereology, Dhulikhel Hospital , KUTH, Dhulikhel, Kavre.

${ }^{3}$ Medical Officer, Emergency Department, Sahid Memorial Hospital, Kalanki, Kathmandu.

\section{Correspondence}

Dr. Dharmandra Kumar Karn

Department of Dermatology

Dhulikhel Hospital, KUTH

Dhulikhel, Kavre

e-mail:- dddkarn@gmail.com

\begin{abstract}
Background

Psoriasis is a chronic skin disease characterized by sharply demarcated, erythematous squamous lesions, with an estimated worldwide prevalence of 0 to $11.8 \%$. Methotrexate (MTX) and cyclosporine (CsA) are well known systemic therapies for moderate to severe chronic plague psoriasis.
\end{abstract}

\section{Objective}

The aim of this study is compare the efficacy of methotrexate and cyclosporine in the treatment of Psoriasis.

\section{Methods}

A prospective randomized study was conducting at the Dhulikhel Hospital, KUTH, Dhulikhel during November 2008 to July 2009 with the objective to compare the effectiveness, side effects and cost of MTX and CsA treatment in a context reflecting normal clinical practice.

\section{Results}

A total of 64 patients ( 33 receiving MTX and 31 receiving CsA) were enrolled. These patients were followed every week for first month and their PASI score and side effects were recorded at 0,1 st, 2 nd and 3rd month interval. In the study, the mean ( \pm S.E) PASI score at base line was $23.34 \pm 1.12$ for MTX and $21.25 \pm 1.07$ for CSA group. After 12 weeks of treatment the mean \pm S.E PASI score found to be $5.37 \pm 0.42$ for MTX and $4.56 \pm 0.41$ for CsA group. The difference in the response between the groups acquired statistically not significance $(p=0.160>0.05)$ meaning there is no difference in the effectiveness of MTX and CsA.

\section{Conclusions}

The efficacy, side effects, ease of administration (once weekly vs. twice daily treatment) and cost, it seems that treatment of psoriasis patient with systemic therapy using MTX is preferable than CSA even though, both have similar clinical efficacy.

\section{Keywords}

Methotrexate, Cyclosporine, Psoriasis. 


\section{Introduction}

Psoriasis is a chronic inflammatory skin disease characterized by a prominent T-cell infiltrate, epidermal hyper proliferation and abnormal keratinocyte differentiation (parakeratosis), infiltration of many different leukocytes and increased vascularity in the dermis ${ }^{1}$. It is systemic immune-mediated disease accompanied by arthritis in a significant percentage of patients called psoriatic arthritis. Psoriasis has a substantial influence on health-related quality of life that is comparable to that of other serious medical conditions e.g. cancer, heart disease, diabetes and depression ${ }^{2}$.

\section{Methods}

This study design was a prospective and twelve-week follow-up study. The total 64 Patients who met the inclusion criteria were collected from Department of Dermatology out patient department of Dhulikhel Hospital KUTH from November 2008 to July 2009. The inclusion criteria were: Subjects of either sex, with age between 18 and 70 years, Patients having PASI $\geq 8$ and previously not treated with either MTX or CsA. The exclusion criteria were: Patients having significant abnormalities in liver and renal function tests, Pregnant and lactating women, Alcoholics, Uncontrolled hypertension, refuse to consent and Patients with chronic underlying disease.

At first, patient who fit the inclusion criteria, were told about the study being done and about their contribution in this study. In the case if the patient was not able to answer or was physically or mentally disable, the informed consent was taken from the patient party.

After taking written consent from patient, standard questionnaire was filled and the information including age, sex, occupation, family history, date of diagnosing of psoriasis, details of medication, life style, time of follow up and clinical (laboratory) finding including complete hematological profile, hepatic and renal function test, chest X-ray, blood sugar test and blood pressure were obtained.

Regarding treatment, the patients were alternatively allocated into two groups, group A and group B. The group A patients were given tablet methotrexate 10 $\mathrm{mg} /$ week. This was continued for three months. Group $\mathrm{B}$ patients were given cyclosporine $2.5 \mathrm{mg} / \mathrm{kg} /$ day in two divided dose for three months. At the time of data collection, PASI calculation was done and ones having more than 8 were taken into account. On every follow up, they were asked about side effects, which they have felt after interval of taking medication and PASI was done at every end of the month. This entire information gathered was entered in the prepared questionnaire. This information was entered in specially designed data entry sheet.

\section{Psoriasis area and severity index (PASI) score calculation}

The current gold standard for assessment of extensive psoriasis has been the Psoriasis Area and Severity Index (PASI.). Fredriksson and Pettersson created the PASI in 1978 as a method to evaluate the clinical efficacy of a new treatment for psoriasis ${ }^{3}$. When using the PASI, psoriatic plaques are graded based on three criteria: redness $(R)$, thickness $(T)$, and scaliness $(S)$. Severity is rated for each index on a $0-4$ scale ( 0 for no involvement up to 4 for very severe involvement). The body is divided into four regions comprising the head $(\mathrm{h})$, upper extremities $(\mathrm{u})$, trunk $(t)$, and the lower extremities. In each of these areas, the fraction of total surface area affected is graded on a $0-6$ scale ( 0 for no involvement up to 6 for greater than $90 \%$ involvement). The various body regions are weighted to reflect their respective proportion of body surface area (BSA). The composite PASI score can then be calculated by multiplying the sum of the individualseverity scores for each region by the weighted area -of - involvement score for that respective region, and then summing the four resulting quantities; mathematically this evaluation is as follows:

\section{Table:1 Steps in generating PASI score}

1. Divide body into four areas: head, arms, trunk to groin, and legs to top of buttocks

2. Generate an average score for the erythema, thickness, and scale for each of the 4 areas ( $0=$ clear; $1-4=$ increasing severity).

3. Sum scores of erythema, thickness, and scale for each area.

4. Multiply score of item (c) above for each area and multiply that by $0.1,0.2,0.3$, and 0.4 for head, arms, trunk, and legs, respectively.

5. Generate a percentage for skin covered with psoriasis for each area and convert that to a $0-6$ scale $(0=0 \% ; 1=1-9 \%$; $2=10-29 \%$; 3=30-49\%; 4=50-69\%; 5=70-89\%; 6=90$100 \%)$.

6. Multiply this score with item resulted from (d).

7. Add these scores to get the PASI score.

The highest potential score is 72 ; the lowest is 0 . PASI scores are nearly continuous, with 0.1 increments within these values. PASI 75 or a reduction in baseline PASI score of $>75 \%$ is the standard used by FDA to assess the efficacy of psoriasis agent. The PASI score and percentage body surface area were the only measures recommended 
by an American Academy of Dermatology (AAD) consensus group to assess extent of psoriasis when planning treatment ${ }^{4}$.

\section{Statistical analysis}

The collected data were compiled and processed using Microsoft Excel 2007. Statistical analysis was carried out by statistical package SPSS 14.5. Both univariate and multivariate statistical methods were used. Data

were represented in the form of mean plus minus SE where applicable. A p- value less than 0.05 were considered to be statistically significant.

\section{Results}

Only a total of $64(77.10 \%)$ patients could be enrolled in the study. All consented to participate in the study. A total of $33(51.56 \%)$ and $31(48.43 \%)$ patients in MTX and in the CsA group were included in the

analysis respectively. The demographic characteristics of the 64 patients included for the analysis of this study are presented in Table 2.

Table: 2 Demographic Characteristics of the Study Population

\begin{tabular}{|c|c|c|c|c|c|}
\hline Variables & Characteristics & $\operatorname{MTX}(n=33)$ & $\operatorname{CsA}(n=31)$ & Total \% & p-value \\
\hline Age (Year) & Mean, SD & $39.48 \pm 11.74$ & $39.45 \pm 9.4$ & ------ & 0.99 \\
\hline \multirow[t]{5}{*}{ Age Groups, Year } & $20-29$ & 8 & 8 & 25 & \\
\hline & $30-39$ & 9 & 8 & 26.56 & 0.59 \\
\hline & $40-49$ & 11 & 9 & 31.25 & \\
\hline & $50-59$ & 3 & 5 & 12.5 & \\
\hline & $60-69$ & 2 & 1 & 4.68 & \\
\hline \multirow[t]{2}{*}{ Gender } & Male & 26 & 26 & 81.25 & 0.001 \\
\hline & Female & 7 & 5 & 18.75 & \\
\hline \multirow[t]{5}{*}{ Ethnic group } & Brahmin & 10 & 6 & 25.00 & 0.81 \\
\hline & Chhetri & 9 & 6 & 23.44 & \\
\hline & Newar & 7 & 13 & 31.25 & \\
\hline & Tamang & 5 & 4 & 14.06 & \\
\hline & Others + & 2 & 2 & 6.25 & \\
\hline \multirow[t]{2}{*}{ Education } & Illiterate & 29 & 20 & 76.56 & 0.92 \\
\hline & Literate & 4 & 11 & 23.44 & \\
\hline \multirow[t]{5}{*}{ Occupation } & Farming & 17 & 21 & 59.38 & 0.76 \\
\hline & Housewife & 4 & 3 & 10.94 & \\
\hline & Service & 9 & 6 & 23.44 & \\
\hline & Shopkeeper & 2 & 0 & 3.13 & \\
\hline & Others ++ & 1 & 1 & 3.13 & \\
\hline
\end{tabular}

Others +: Giri, Pariyar, Rokka, Biswokarma

Others +: Student, Carpenter

SD: Standard Deviation.

The mean age of psoriasis patient was $39.48 \pm 11.74$ for MTX and 39.45 \pm 9.4 for CsA respectively. Both group included in the study have similar age as there is no significant difference (p-value $0.99,>0.05$ from paired sample test).

The sex distribution of the study patients is given in figure 1. Sex was not equally distributed in the MTX and CsA group $(\mathrm{p}=0.001<0.05)$. 


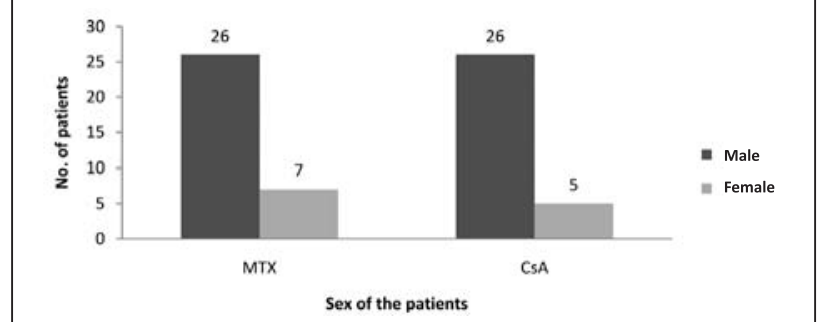

Figure 1 Sex distribution of patients

The anthropometric measurements of the patients are shown in Table 3. The mean body weight of MTX patients was $63.09 \pm 8.13 \mathrm{~kg}$ where as it was $59.64 \pm 9.13$ for CsA patients. There was no significant difference in terms of weight between two groups $(p=0.108>0.05)$.

Table: 3 Anthropometric Measurements

\begin{tabular}{lccc}
\hline Variables & MTX $(n=33)$ & CSA $(n=33)$ & p-value \\
\hline \multirow{2}{*}{ Weight } & $63.09 \pm$ & $59.64 \pm$ & \\
& 8.13 & 9.13 & 0.108 \\
& & & \\
BMI $\left(\mathrm{Kg} / \mathrm{m}^{2}\right)$ & $26.01 \pm$ & $26.14 \pm$ & 0.299 \\
& 4.85 & 4.67 & \\
\hline
\end{tabular}

Similarly, mean BMI was $26.01 \pm 4.85 \mathrm{Kg} / \mathrm{m}^{2}$ for MTX while it was $26.14 \pm$

$4.67 \mathrm{Kg} / \mathrm{m}^{2}$ for CsA users. Subjects in both groups have same BMI $(p=0.299>0.05)$.

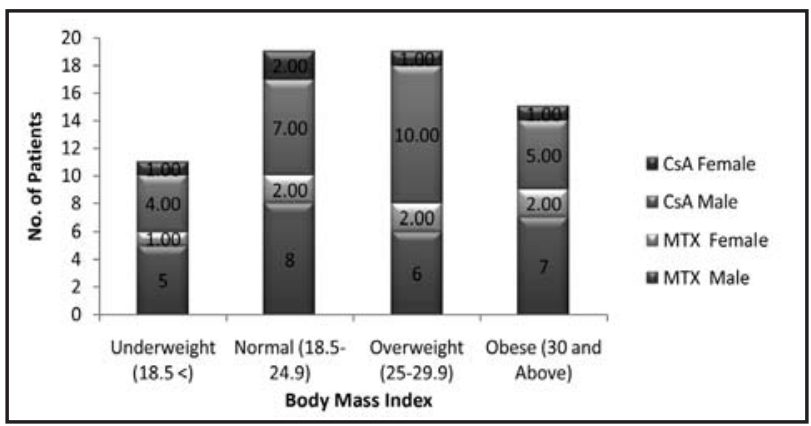

Figure 2 Distribution of the Body mass index of patients

In both groups, equal distributions of patients were found to be normal BMI $\left(18.5-24.9 \mathrm{Kg} / \mathrm{m}^{2}\right)$ and overweight BMI $\left(25-29.9 \mathrm{Kg} / \mathrm{m}^{2}\right)$, followed by obese $(\geq 30)$.

\section{Smoking status of the patient}

Cigarette smoking is the most important cause of psoriasis ${ }^{2}$. Among 64 patients only $22.6 \%$ were nonsmoker while $70.9 \%$ were ex-smoker and had left after

diagnosis of having psoriasis and $6.5 \%$ were still smoking. This also reveals that cigarette smoking is the most important risk factor of psoriasis.

Table: 4 Personal History of the Patients

\begin{tabular}{|c|c|c|c|c|}
\hline Variables & Characteristics & $\begin{array}{c}\operatorname{MTX}(n=33) \\
(n=\%)\end{array}$ & $\begin{array}{c}\operatorname{CsA}(n=31) \\
(n=\%)\end{array}$ & $p$-value \\
\hline \multirow[t]{3}{*}{ Smoking Status } & Non-Smoker & $4(12.12)$ & $7(22.6)$ & 0.85 \\
\hline & Ex-Smoker & $29(87.88)$ & $22(70.9)$ & \\
\hline & Smoker & 0 & $2(6.5)$ & \\
\hline \multirow[t]{3}{*}{ Smoking Sticks per day } & Less than 9 & $6(20.69)$ & $5(20.83)$ & \\
\hline & Ten to 15 & $15(51.72)$ & $17(70.83)$ & \\
\hline & Fifteen to 20 & $8(27.59)$ & $2(8.33)$ & 0.55 \\
\hline \multirow[t]{3}{*}{ Alcohol } & Never & $26(78.78)$ & 19 (61.29) & \\
\hline & Sometimes & $7(21.21)$ & $11(35.48)$ & 0.86 \\
\hline & Regular & & $1(3.22)$ & \\
\hline
\end{tabular}

\section{Family history of psoriasis}

A detail of family history of psoriasis is given in figure 3

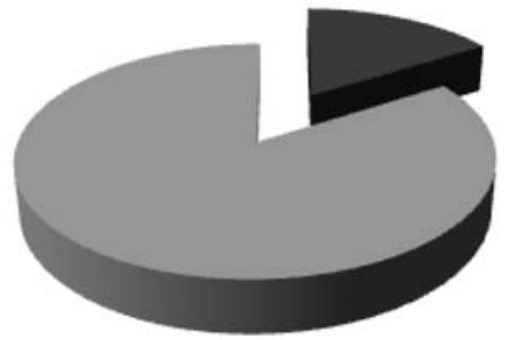

Figure:3 Family history of psoriasis

\section{Medication history}

Most of the patients (51.56\%) had previously used topical mono-therapy either with corticosteroid, or salicylic acid preparation followed by emollients only (20.31\%).

Since patients under systemic treatment with either MTX or CsA were not included in the study. So using topical preparations are only included in the study. A detail of medication history is given in figure 4 
Figure 4 past medication history

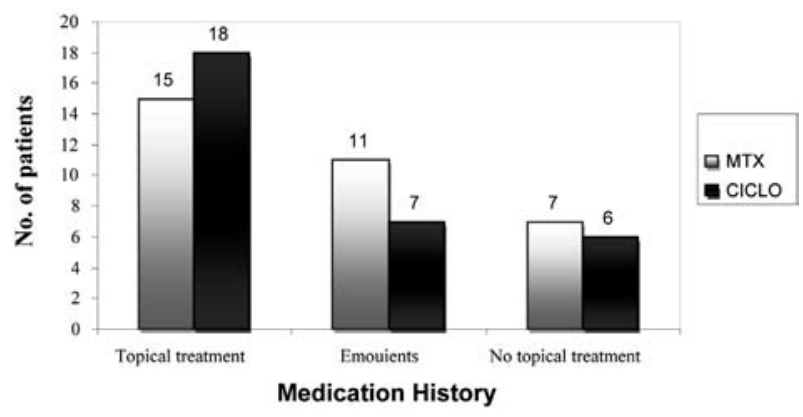

\section{Efficacy}

The comparative PASI score of MTX and CsA group patients are shown in Table 5

Table: 5 Comparative PASI Score at different months and its statistics
Figure 5 Psoriasis Area and Severity Index (PASI) scores at 4,8 , and 12 weeks of treatment. Results are shown as mean $\pm 95 \%$ confidence interval.

Successful treatment (defined as $>75 \%$ reduction of the baseline PASI score, PASI 75) was achieved by $57.57 \%$ in the MTX group and $67.74 \%$ in the CsA group.

Almost complete remissions (defined as $>90 \%$ reduction of the baseline PASI score) was achieved by $9.09 \%$ of the patients in MTX group and by $12.09 \%$ in the CsA group (not significant, n.s.). About (42.42\%) of the patients in MTX group and $29.03 \%$ in CsA group achieved moderate improvement (50-74\%) in PASI score compared with baseline. One (3.25\%) patient of CsA group failed to achieve moderate improvement.

\begin{tabular}{lcccc}
\hline Variable & Base month (mean \pm SE) & 1 month & 2 month & 3 month \\
\hline MTX $(n=33)$ & $23.34 \pm 1.12$ & $15.60 \pm 0.72$ & $9.45 \pm 0.52$ & $5.37 \pm 0.42$ \\
CSA ( $n=31)$ & $21.25 \pm 1.07$ & $14.50 \pm 0.66$ & $8.45 \pm 0.57$ & $4.56 \pm 0.41$ \\
z-value & 2.53 & 2.05 & 1.65 & 1.44 \\
p-value & $0.017(S)$ & $0.049(\mathrm{~S})$ & 0.110 (NS) & 0.160 (NS) \\
\hline
\end{tabular}

In this study, the mean $( \pm \mathrm{SE})$ PASI score of disease at base line was $23.34 \pm 1.12$ for MTX and 21.25 \pm 1.07 for CsA. After four weeks of treatment the mean $( \pm$ SE) PASI score was $15.60 \pm 0.72$ and $14.50 \pm 0.66$, respectively. The difference in the response between the groups acquired statistical significance at base month and first month $(\mathrm{p}=$ 0.017; 0.049) meaning that CsA was more effective than MTX.

At eighth and $12^{\text {th }}$ week of treatment the mean $( \pm \mathrm{SE})$ PASI score found to be $9.45 \pm 0.52$ for MTX and 8.45 \pm 0.57 for CsA and $5.37 \pm 0.42$ for MTX and $4.56 \pm 0.41$ for CsA group. The difference in the response between the groups acquired statistically not significance $(\mathrm{p}=$ $0.110 ; 0.160>0.05$ ) meaning that there is no difference in the effectiveness of MTX and CsA after two months of treatment. Figure: 5 demonstrates the relative change of the mean PASI in treatment groups.

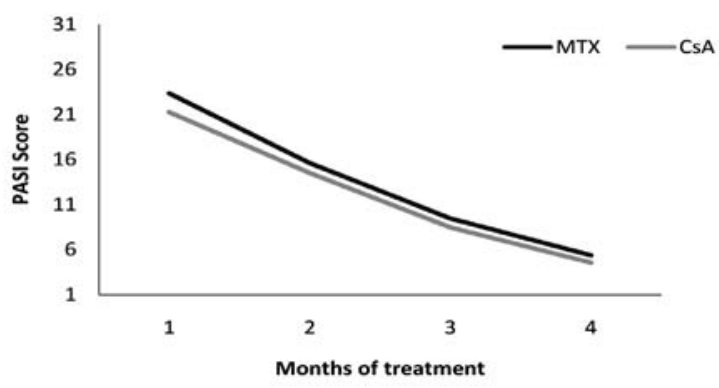

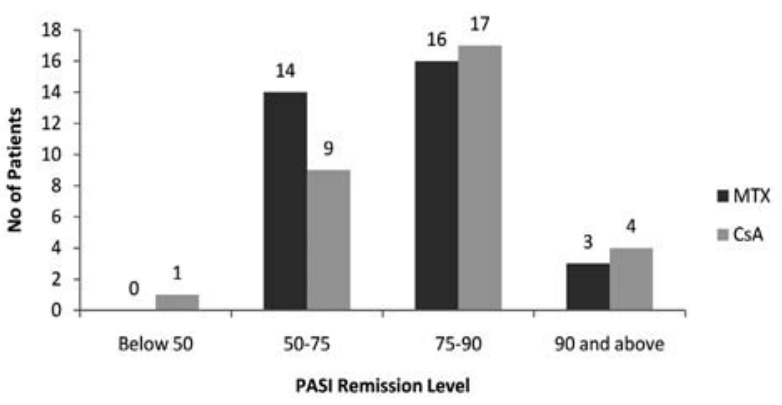

Fig. 6 PASI Remission level after the administration of MTX and CsA

\section{Side effects profile of study patients}

The detailed side effects profiles of both the drugs are given in the table 6

We found that number of side effect experienced by the patients in cyclosporine were more than the patient on MTX grouped. About (69.69\%) of the patient in MTX group and (97\%) in the CsA reported side effects. Significantly more patients in the CsA group reported fatigue ( 17 of 31 vs. 5 of 33) in MTX group, $\mathrm{p}=0.000<$ $0.05)$.

Equal percentage (48.28\%) of CsA reported infection and paresthesis in finger tips and toes vs. (34.78\% and $0 \%$ of MTX reported respectively. About $30.43 \%$ of MTX group and $20.69 \%$ of CsA group reported elevated liver enzyme and hypertension respectively; $(\mathrm{p}=0.003<$ 0.05 ) which was statistically significant. 
Table: 6 Side effects of study patients

\begin{tabular}{lccc}
\hline Side Effects & $\begin{array}{c}\text { MTX (n=33) } \\
(\mathbf{n}=\%)\end{array}$ & $\begin{array}{c}\text { CsA (n=31) } \\
(\mathbf{n}=\%)\end{array}$ & p-valule* \\
\hline Nausea & $8(34.78)$ & $3(10.34)$ & .110 \\
Vomiting & $2(8.70)$ & $1(3.45)$ & .324 \\
Abdominal Pain & $4(17.39)$ & $3(10.34)$ & .534 \\
Fatigue & $5(21.74)$ & $17(58.62)$ & .000 \\
Infection & $8(34.78)$ & $14(48.28)$ & .201 \\
Headache & $5(21.74)$ & $11(37.93)$ & .160 \\
Parasthesis & $0(0.00)$ & $14(48.28)$ & .000 \\
Anthralgia & $4(17.39)$ & $5(17.24)$ & .534 \\
Myalgia & $0(0)$ & $6(20.69)$ & .006 \\
Muscle cramp & $0(0)$ & $7(24.14)$ & .006 \\
Hypertension & $0(0)$ & $6(20.69)$ & .003 \\
Urgency & $1(4.35)$ & $2(6.90)$ & .571 \\
Elev. Liver enzyme & $7(30.43)$ & $0(0)$ & .003 \\
\hline
\end{tabular}

${ }^{*} \mathrm{p}$-value is obtained by using paired sample t-test; the percentage may exceed 100 due to the multiple responses

\section{Cost analysis}

Table: 7 Cost comparisons of MTX and CsA

\begin{tabular}{lcc}
\hline Description (per patient) & MTX & CsA \\
\hline Average dose & $10 \mathrm{mg} /$ week & $150 \mathrm{mg} /$ day \\
Cost (Rs) & $30.00 / 10 \mathrm{mg}$ & $172.50 / 150 \mathrm{mg}$ \\
Cost per month & 120.00 & $5,175.00$ \\
Cost per three month & 360.00 & $15,525.00$ \\
\hline
\end{tabular}

Drug cost of unit dose for MTX was found to be very lesser than that of CsA.

\section{Discussion}

In this study, most of the patients (31.25\%) with the age group of 40-49 years were found in both groups and more than $80 \%$ of patients had disease onset before 49 years. A large study in China reported that about $75 \%$ had disease onset before the age of 46 years $^{5}$.

Numbers of male patients were found more in both groups. This is because females tend to be negligent about health. There is no evidence that disease is phenotypically different between the sexes ${ }^{5}$.

According to Hoffman et al, smoking and increased BMI represent modifiable risk factor for psoriasis and may influence clinical severity and prognosis ${ }^{6}$. However, in our study also more than $26.58 \%$ patients have increased BMI and about $30.3 \%$ patients have normal body weight at the time of disease onset.

While analyzing, among the smokers most of the patients in both groups used to consume more than 15 sticks per day. There was no significance difference in smoking habit between two groups ( $p$-value0.55>0.05).
According to Fortes et al smoking more than 20 stick per day have 2 -fold increased risk of having severe disease ${ }^{7}$.

Alcohol seems to play no significant role on psoriasis as $70 \%$ of the patients had never used alcohol. Occasionally 7 in MTX and 11 in CsA group were consuming alcohol and only one subject was having alcohol regularly [about half a glass daily]. The patient's habits of taking alcohol in both groups were equally distributed and statistically, there was not significant ( $\mathrm{p}=0.86>0.05)$. According to Gudjonsson et al, there is no disease onset with alcohol intake but can exacerbate preexisting disease ${ }^{2}$.

The family history of psoriasis in both groups was equally distributed and statistically, there was not significant $(p=0.181)$. Overall we found that $16 \%$ of patients have family history of psoriasis. However Raychaudhuri et ai; found that $54 \%$ of the adult had positive prevalence of family history ${ }^{8}$ which is very higher prevalence rate than our study. This is because most of the patients in our study were unaware about their parent's disease status, which might have restricted out data collection. In our study, duration and the sample size is also less.

Overall, the mean percent reduction of PASI score from base week to 12 weeks of treatment, was found to be 76.63 \pm 1.79 for MTX and $77.84 \pm 1.92$ for CsA ( $\mathrm{p}=0.690>$ $0.050)$ compared with baseline(n.s.) which is higher than that of flytstorm et $\mathrm{al}^{9}$. The results of our study show equal effectiveness of MTX as compared to CsA at 12 weeks of treatment. A considerably lower percent of the patients in both groups reached PASI 75, compared with a previous study ${ }^{10}$. We believe that a possible explanation might be a minimum dose of treatment used in our study.

Gastrointestinal effect including nausea and vomiting were reported by both grouped patients which wasn't statistically significant.No additional medication is required to relieve side effect in either group. No serious or irreversible side effects were observed thorough out study.

Flytstrom et al, reported more side effects in compared to our study which might be due to high drug dose used i.e maximum $15 \mathrm{mg} /$ weekly and $5 \mathrm{mg} / \mathrm{kg} /$ day of MTX and CsA respectively?.

Strober et.al, recommend that patients on MTX therapy should have supplemental folic acid at 5mg/ day including the day of MTX dosing to avoid gastrointestinal effect ${ }^{11}$. Since psoriasis is a very common chronic relapsing diseases improve an enormous burden on society in terms of lowered quality of life, decreased work-force participation and increased health care expenditure. The socioeconomic status of Nepalese people is low, particularly in the study area (Dhulikhel). 
The cost analysis would be helpful in recommending the affordable one between two therapeutically equivalent drugs. In this case, MTX was found to be therapeutically equivalent to CsA and is cheaper one.

\section{Conclusion}

Our study concluded that both the study drugs (MTX and CsA) were equally effective in terms of efficacy. The cost of treatment with MTX was found to be much lesser than that of CsA. Average total cost for individual patient achieving PASI 75, is Rs.360.00 for MTX and Rs.15, 525.00 for CsA. The number of side effects observed in MTX is statistically significant to that of CsA.

Overall evidences from efficacy, side effects, ease of administration (once weekly vs. twice daily treatment) and cost, it seems that treatment of psoriasis patient with systemic therapy using MTX is preferable than CsA even though, both have similar clinical efficacy.

\section{References}

8. Wendy AM, Gottlieb AB, Mease P. Psoriasis and psoriatic arthritis: clinical features and disease mechanisms. Clinics in Dermatology 2006; 24: 438-47.

9. Gudjonsson JE, Elder JT. Psoriasis: epidemiology. Clinics in Dermatology 2007; 25: 535-46.

10. Fredriksson T, Pettersson U. Severe psoriasis-oral therapy with a new retinoid. Dermatologica 1978; 157 (4):238-44.

11. Callen JP, Krueger GG, Lebwohl M, McBurney EI, Mease P, Menter A, Paller AS, Pariser DM, Weinblatt M, Zimmerman G. AAD consensus statement on psoriasis therapies. J Am Acad Dermatol 2003; 49 (5): 897-99.

12. Griffiths CEM, Camp RDR and Barker JNWN in : Burns T, Breathrochs, Cox N, Griffiths C, EDs, Rook's Text book of Dermatology, Vol. 1, Eight Edition, Blackweek Publishing, 2010, $20.1-20.60$.

13. Herron MD, Hinckley M, Hoffman MS, et al. Impact of obesity and smoking on psoriasis presentation and management. Arch Dermatol 2005; 141:1527-34
14. Fortes C, Mastroeni S, Leffondre K, et al. Relationship between smoking and the clinical severity of psoriasis. Arch Dermatol 2005; 141:1580-4.

15. Raychaudhuri PS et al. A comparative study of Pediatric onset psoriasis with adult onset psoriasis. Pediatric Dermatology 2000; 17:3,174-78.

16. Flytstrom I, Gtenberg B, Svenssson A and Bergbrant I-M. Methotrexate vs. Ciclosporine in psoriasis: effectiveness, quality of life and safety. A randomized controlled trial. $\mathrm{Br}$ J Dermatol; 2008:158:116-21

17. Heydendael VM, Spuls PI, Opmeer BC et al. Methotrexate vs cyclosporine in moderate-to-severe chronic plaque psoriasis. N Engl J Med 2003; 349: 658-65

18. Strober BE, Menon K. Folate supplementation during methotrexate therapy for patients with psoriasis. J Am Acad Dermatol 2005; 53:652-59. 